\title{
Endoscopic closure of tracheoesophageal fistula with a novel dumbbell-shaped occluder
}

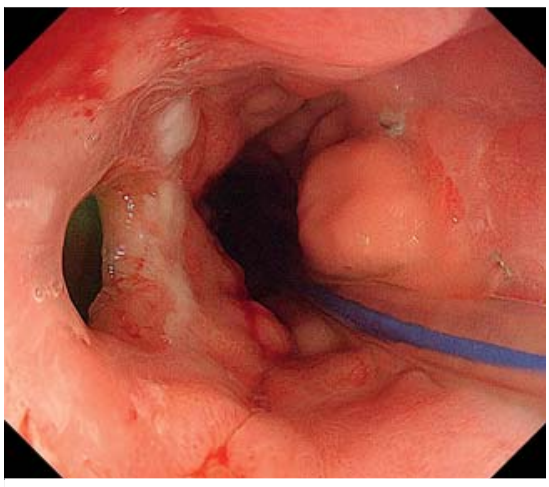

- Fig. 1 View during gastroscopy showing a fistula between the esophagus and the tracheal wall, with a nasogastric tube seen inside the esophageal lumen.

Tracheoesophageal fistula (TEF) is a challenging condition that is difficult to treat. Several reports have described successful TEF treatment with an Amplatzer occlu$\operatorname{der}$ (AGA Medical Corporation, Plymouth, Minnesota, USA) [1,2]. However, Daniel et al. reported the case of a benign gastrobronchial fistula patient who underwent treatment with the Amplatzer device and died of fatal hemoptysis [3]. Inspired by this case, we developed a new dumbbell-shaped occluder device [4]. Compared with the Amplatzer occluder, this device has no protrusions, which reduces the risk of bleeding; even if the patient coughs, it will not increase airway damage.

A 69-year-old man with a chronic TEF was the first patient to be successfully treated with our novel occluder ( $\downarrow$ Video 1 ). He had been diagnosed 7 years previously with esophageal cancer and underwent surgery. He presented 1 year prior to treatment with cough, aspiration, and weight loss. An endoscopic examination revealed a tracheoesophageal fistula 27 $\mathrm{cm}$ from the incisors ( $>$ Fig. 1 ), with a diameter of $0.8 \mathrm{~cm}$. After several esophageal stent placements and replacements and anastomotic sutures, there was still evidence of difficulty in healing of the

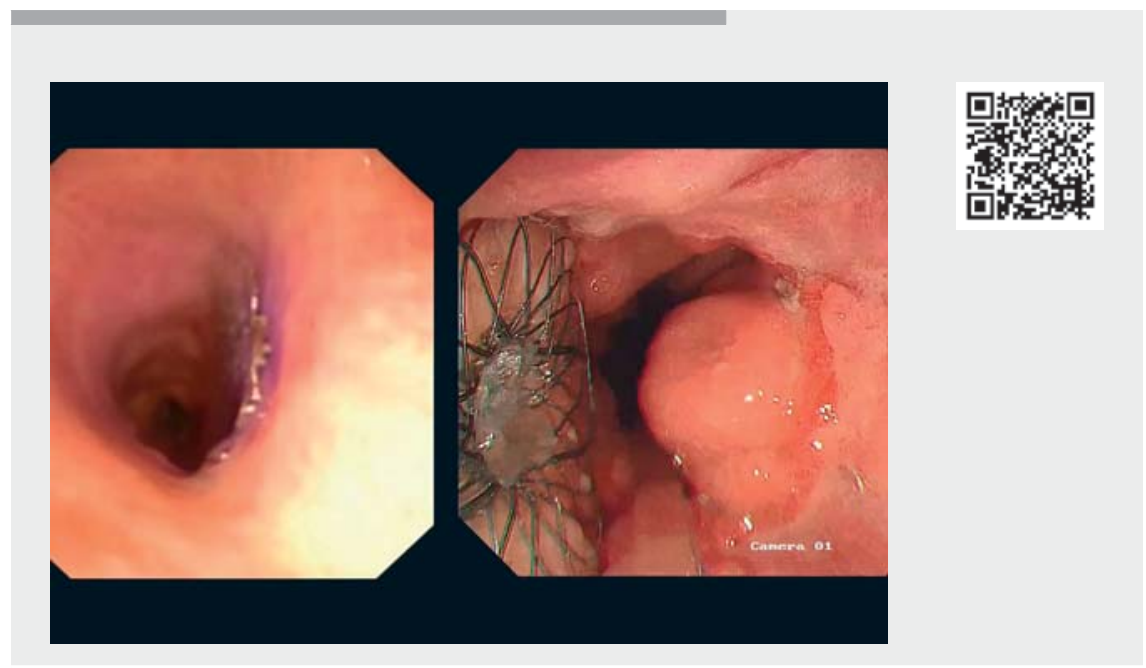

$\checkmark$ Video 1 Treatment of a tracheoesophageal fistula (TEF) by gastroscopy and bronchoscopy, using a newly developed dumbbell-shaped occluder.

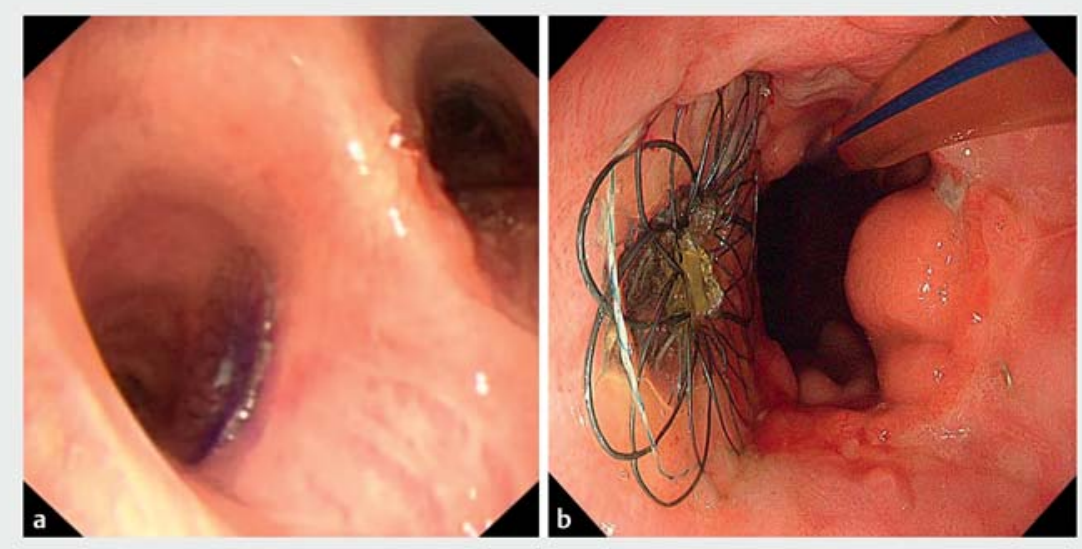

Fig. 2 Endoscopic images showing the orifices of the fistula occluded by the occluder device on: a bronchoscopic view; b gastroscopic view.

fistula. We therefore decided that application of this new instrument was an appropriate treatment strategy.

We inserted a 9-Fr catheter through the endoscope, so that the device could be introduced into the airway. After releasing the distal dilation disc under direct vision with a bronchoscope, we gently pulled the device until it was fixed against the airway wall ( $>$ Fig. 2 a). As the flexible catheter was removed, we observed that the side of the gastroscope slowly pulled the device to release the proximal expansion disc (-Fig. 2 b).

The patient tolerated a normal diet after 2 days. By the 4-month follow-up, all of his clinical symptoms had been relieved, and his body mass index had increased 


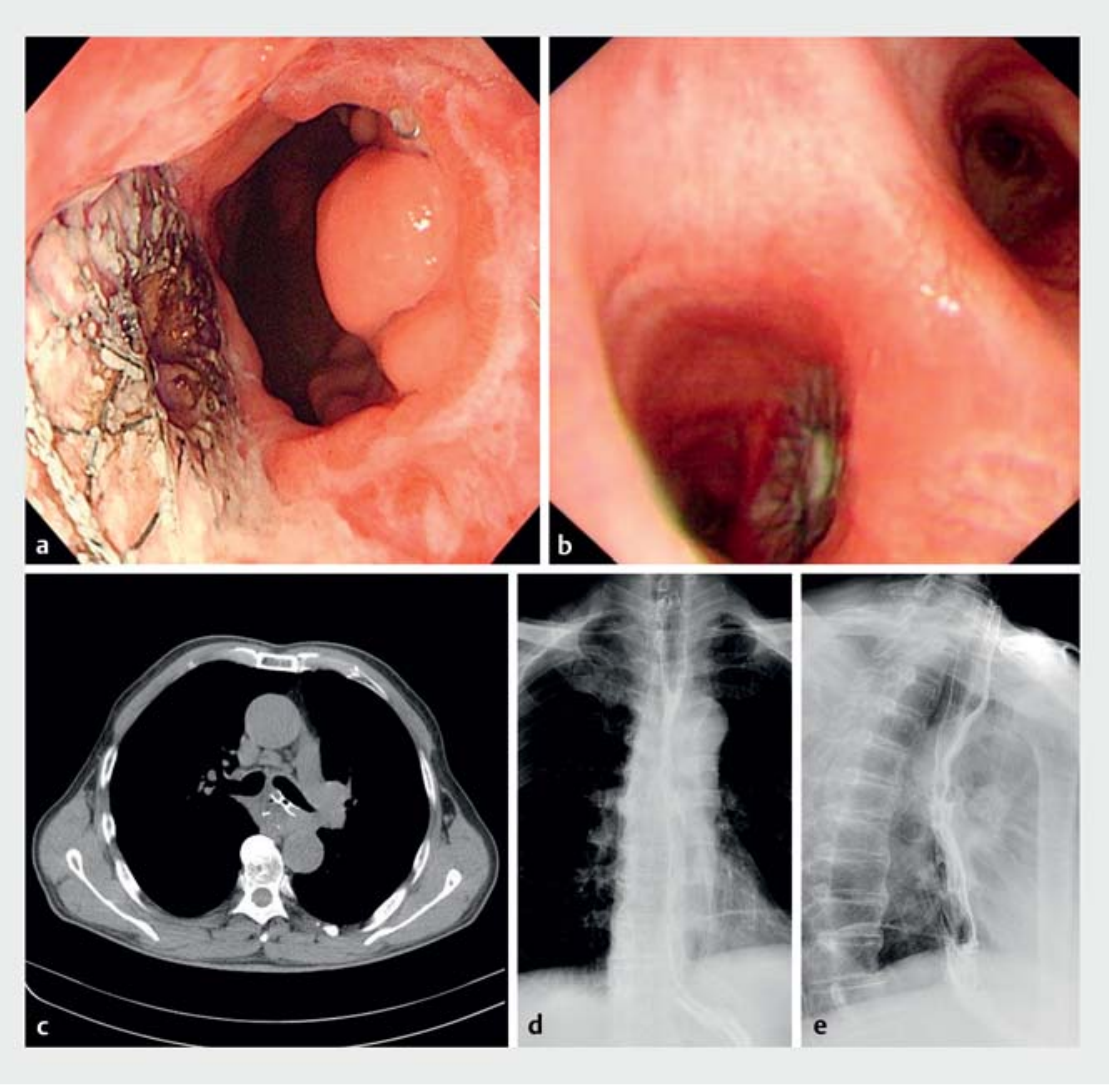

- Fig. 3 Follow-up at 4 months showing: a the appearance of the occluder device on gastroscopy; $\mathbf{b}$ the bronchoscopic appearance; $\mathbf{c}$ the occluder placed between the esophageal and tracheal walls on axial computed tomography (CT) scanning; d, e no contrast extravasation after blocking contrast examination of the tracheoesophageal fistula.

from $18.5 \mathrm{~kg} / \mathrm{m}^{2}$ to $23.6 \mathrm{~kg} / \mathrm{m}^{2}$. Gastroscopy and tracheoscopy evaluations showed that the fistula was completely blocked, and no leakage was found on gastrointestinal radiography and computed tomography ( $\triangleright$ Fig. $\mathbf{3}$ ).

The findings of the present case demonstrate that our newly developed dumbbell-shaped occluder can effectively block a TEF, thereby providing a new method for mechanical TEF closure.

Endoscopy_UCTN_Code_TTT_1AO_2AI

Funding

National Natural Science Foundation of China,

http://dx.doi.org/10.13039/

501100001809

81570578

\section{Competing interests}

The authors declare that they have no conflict of interest.

The authors

Chang Zhu, Lurong Li, Yun Wang, Weifeng Zhang, Wenjie Li, Xuan Li ${ }^{\odot}$, Guoxin Zhang China

Corresponding author

\section{Guoxin Zhang, MD}

Department of Gastroenterology, First Affiliated Hospital of Nanjing Medical

\section{References}

[1] Repici A, Presbitero P, Carlino A et al. First human case of esophagus-tracheal fistula closure by using a cardiac septal occluder (with video). Gastrointest Endosc 2010; 71 : 867-879

[2] Guturu P, Bilal M, Rangasetty U et al. Endoscopic closure of esophagopleural fistula with Amplatzer atrial septal defect closure device. Am J Gastroenterol 2019; 114: 198

[3] Buitrago DH, Pinto D, Berkowitz S] et al. Fatal hemoptysis after closure of gastrobronchial fistula using an Amplatzer vascular device. Ann Thorac Surg 2018; 105 : e71-e73

[4] Sang H, Peng L, Zhang G. Tracheoesophageal fistula closed by a new gastrointestinal occluder device. Endoscopy 2020. doi:10.1055/a-1234-6702

\section{Bibliography}

Endoscopy 2022; 54: E334-E335

DOI 10.1055/a-1524-0761

ISSN 0013-726X

published online 19.7.2021

(c) 2021. Thieme. All rights reserved.

Georg Thieme Verlag KG, Rüdigerstraße 14, 70469 Stuttgart, Germany

\section{ENDOSCOPY E-VIDEOS}

https://eref.thieme.de/e-videos Department of Gastroenterology, First Affiliated Hospital of Nanjing Medical University, Nanjing, University, 300 Guangzhou Road, District of Gulou, Nanjing 210029, P. R. China guoxinz@njmu.edu.cn

\section{website at}

https://mc.manuscriptcentral.com/e-videos
Endoscopy E-Videos is an open access online section, reporting on interesting cases and new techniques in gastroenterological endoscopy. All papers include a high quality video and all contributions are freely accessible online. Processing charges apply (currently EUR 375), discounts and wavers acc. to HINARI are available.

This section has its own submission 